\title{
Parental perception of child's body weight status and its association with socio-demographic factors among Malay children in primary schools in Kuala Terengganu, Malaysia
}

\author{
Nurzaime Zulaily ${ }^{1}$, Aryati Ahmad ${ }^{1 *}$, Mohd Razif Shahri1 ${ }^{1}$ \& Amran Ahmed ${ }^{2}$ \\ ${ }^{1}$ School of Nutrition and Dietetics, Faculty of Health Sciences, Gong Badak Campus, \\ Universiti Sultan Zainal Abidin, 21300 Kuala Nerus, Terengganu, Malaysia; ${ }^{2}$ Institute \\ of Engineering Mathematics, Pauh Putra Campus, Universiti Malaysia Perlis, 02600 \\ Arau, Perlis, Malaysia
}

\begin{abstract}
Introduction: Obesity rate among school children has increased globally. Parental perception plays a significant role in the management of obesity among children. Previous studies indicated that parents who accurately perceived their child's body weight status (BWS) tended to encourage healthy behaviours as compared to parents who overlooked the problem. Therefore, this study aimed to determine the association between socio-demographic factors with parental perceptions of their child's BWS among school children in Terengganu, Malaysia. Methods: Using a cross-sectional study design, 389 school children aged 9 to 11 years old were recruited. Height and weight were measured using calibrated tools and inputted into the World Health Organization AnthroPlus software for body mass index $z$-score calculation. Parental perceptions of their child's BWS were explored using a selfadministered questionnaire together with their socio-demographic background. Results: Of 389 subjects, $53.2 \%$ of school children were from rural and $46.8 \%$ were from urban schools. Overall, mean BMI-for-age $z$-score between school locations showed no significant difference, with higher means reported in urban $(-0.2 \pm 1.6 S D)$ than in rural $(-0.4 \pm 1.6 S D)$. Significant association was found between parents' perceptions and actual BWS $(p<0.001)$. Logistic regression analysis showed that parents of overweight children and parents in rural schools were more likely to misperceive their child's BWS. Conclusion: This finding suggests that parents from rural areas and having overweight children were more likely to have misperceptions of their child's BWS. Therefore, knowledge-based intervention programmes among parents specifically in the rural areas are needed to increase the level of awareness to assist in obesity prevention.
\end{abstract}

Keywords: Parental perception, body weight, school children, Terengganu

\section{INTRODUCTION}

A child's lifestyle and body weight status (BWS) are strongly influenced by their surrounding environment including their family and home environment. Home and family environment can either be "obesogenic" or "leptogenic", depending on how they were designed (Rosenkranz

\footnotetext{
${ }^{*}$ Corresponding author: Dr Aryati Ahmad

School of Nutrition and Dietetics, Faculty of Health Sciences, Gong Badak Campus,

Universiti Sultan Zainal Abidin, 21300 Kuala Nerus, Terengganu, Malaysia

Tel: (6)09-6688519; Fax: (6)(09)6687978; E-mail: aryatiahmad@unisza.edu.my

doi: https://doi.org/10.31246/mjn-2019-0089
} 
\& Dzewaltowski, 2008). At this microlevel, parents play a critical role in shaping their child's activity pattern, dietary intake and overall attitude towards food (Sleddens et al., 2014). In addition, parenting style practised by the parents may also predict the children's dietary and activity behaviours. Based on the Baumrind's parenting typologies which are Authoritarian, Authoritative, and Permissive, "Permissive" parenting style is associated with an obesogenic environment, whilst "authoritative" parents are linked with leptogenic environments (Johnson et al., 2012). Thus, effective parenting styles are crucial to build a foundation of healthy practices and maintain healthy BWS among children.

Previous evidence has asserted parental roles in efforts to prevent and manage weight-related problems in children (Chen et al., 2014). The level of support on positive and healthy activity behaviours in the family is determined by how the parents perceive their child's BWS and health. Parents who accurately perceive their child as having body weight problem tend to encourage their children to engage in positive healthy behaviours as compared to parents who overlook the problem (Tschamler et al., 2010). In agreement, recent evidence by Katz found that parents have a high tendency to misperceive and overlook BWS of their child, which is referred to as 'oblivobesity' (Katz, 2015). Parents failed to recognise the weight problem faced by their children, hence, lifestyle changes related to weight control and management were less likely to occur. Nonetheless, previous literature had identified several factors associated with an increase in the misperception including child's BWS, education level, socioeconomic status, and sociocultural influences (Duncan et al., 2015; Eckstein et al., 2006; Genovesi et al.,
2005; Hearst et al., 2011; Jones et al., 2011; Young-Hyman et al., 2000).

A recent review by Tompkins, Seablom \& Brock (2015) on parents' perceptions of their children's BWS reported that about $13.3 \%$ to $100 \%$ of parents with overweight children underestimated their child's weight, instead perceiving their child to have a normal weight. Despite the international evidence on parental misperception of BWS, the studies conducted in Malaysia are still limited. Majority of local studies exploring parental perception on child's BWS were conducted in the central Peninsular area including Kuala Lumpur and Selangor (Kok \& Yit, 2019; Muhammad et al., 2008; Serene Tung, Shamarina \& Mohd Nasir, 2011), whilst studies in the East Coast area especially in Terengganu are still in its infancy. Therefore, the aim of this study was to determine the association between children's age, gender, school locality, family income and family size with parental perception of their child's BWS among 9 to 11 years old school children in Terengganu.

\section{MATERIALS AND METHODS}

\section{Study design and sampling}

A cross-sectional study was conducted from February 2016 to September 2016 involving parents of primary school children aged 9 to 11 years from government schools located within the Kuala Terengganu district. All subjects involved in this study were Malays. Six primary schools in Kuala Terengganu were randomly selected from rural and urban locations based on a list obtained from the Terengganu State Department of Education (JPNT). Schools within the district were classified as rural and urban by JPNT based on certain criteria including population density, total population and facilities. 


\section{Study protocol}

This cross-sectional study was conducted after obtaining ethical approval from the Universiti Sultan Zainal Abidin Human Research Committee (UHREC) and permission from JPNT. This study involved self-reported questionnaires and anthropometric measurements. Parental consent for subjects' participation was obtained prior to anthropometric measurements.

\section{Anthropometric measurements}

Body weight and height were measured using calibrated scales (Tanita BC 587 Innerscan Body Composition Monitor and Seca 217 Portable Stadiometer) to the nearest $0.1 \mathrm{~kg}$ and $0.1 \mathrm{~cm}$, respectively. Data on height, weight, gender, and age of each subject were inputted into the World Health Organization (WHO) AnthroPlus software (WHO, 2009) to calculate the body mass index (BMI)-forage $z$-score (BAZ). Age of each subject was calculated to the precise day by subtracting the date of birth from the date of measurement, while BMI was calculated by dividing body weight in kilograms $(\mathrm{kg})$ with height in metre squared $\left(\mathrm{m}^{2}\right)$. During data collection, all subjects were apparently healthy and all measurements were taken in light sports attire without shoes during the mornings or early afternoons. BMI categories were defined using age- and sex- specific cut-off points relative to the 2007 WHO classifications (WHO, 2007). The interpretation of the cut-offs classifies overweight as having a $z$-score $>+1$ standard deviation $(S D)$ (equivalent to BMI $25 \mathrm{~kg} / \mathrm{m}^{2}$ at 19 years), obesity as having a $z$-score $>+2 S D$ (equivalent to BMI $30 \mathrm{~kg} / \mathrm{m}^{2}$ at 19 years) and underweight as having a $z$-score $<-2 S D$. Overweight and obese categories based on researchers' measurements were combined to compare with parent's reported perception of their child's BMI categories. To simplify parental assessment in perceiving their child's body weight status, only three BMI categories (underweight, just about the right weight, or excessive weight) were used, as adapted from the National Health and Nutrition Examination Survey III (Maynard et al., 2003).

\section{Self-administered questionnaire}

The self-administered questionnaire was distributed to each subject with detailed explanation on each question. It was completed by the parent at home and was then collected one week later. The questionnaire had three sections and took approximately three to five minutes to complete. Section 1 gathered information on demographic characteristics including child's age, gender, family member, parental education level, parental age, and household monthly income. The three questions in Section 2 assessed the parents' perceptions of their child's BWS. The first question assessed parents' perceptions of their child's weight using the question, "I feel my child is..." (response options: underweight, about the right weight, or overweight). This was followed by the question "Did your child's doctor ever tell you that your child is gaining weight too fast or is overweight?" (response options: yes or no). Then, it was followed by the question "Did your child's doctor ever tell you that your child is lack of weight?" (response options: yes or no). The five questions in Section 3 assessed parental attitude about the health effects of overweight, their child's body weight status and their degree of influence on their child's food choices. Five-point Likert scale response choices were provided for these questions (response options: strongly agree, agree, neutral, disagree, or strongly disagree). The questionnaire on parents' perceptions of their child's BWS and parental attitude on health was adapted from a previously validated 
questionnaire (Eckstein et al., 2006) and was translated into Bahasa Malaysia with back-to-back translation by an independent translator. A pilot study was conducted and the questionnaire showed an internal consistency of 0.735 , thus indicated an overall good reliability.

\section{Data analysis}

A new binary variable (yes/no) was created to identify the agreement between parental perceptions and the actual BWS of their children. The agreement was 'no' when parents incorrectly classified their child's BWS. The agreement was 'yes' if parents correctly classified their child's BWS with the actual BWS as measured by the researchers. All statistical analyses including creating the new binary variable were conducted using IBM SPSS Statistics for Windows, Version 22.0 software (IBM Corporation, Armonk, New York, USA). Statistical significance was accepted at $p<0.05$. Independent sample $t$-test was used to examine the variation in continuous variables between two groups, whilst association between categorical variables were assessed using chi-square test. Simple logistic regression was performed to determine the associated factors of parental misperception. Then, all significant variables $(p<0.25)$ were included in the multiple logistic regression analysis. The final parsimonious model of associated factors of misperception using multiple logistic regressions was checked for fitness using the Hosmer-Lemeshow goodness-of-fit test.

\section{RESULTS}

\section{Anthropometric characteristics and socio-demographic factors}

Of the 389 subjects who completed the questionnaires, $53.2 \% \quad(n=207) \quad$ were from rural and $46.8 \%(n=182)$ were from urban schools (Table 1). Overall, mean BAZ between school locations showed no significant difference between rural and urban subjects. Mean BAZ was higher in urban $(-0.2 \pm 1.6 S D)$ than in rural $(-0.4 \pm 1.6 S D)(p=0.404)$. In total, the prevalence of underweight, normal and overweight were $11.8 \%, 59.4 \%$ and $28.8 \%$ respectively. Socio-demographic factors of subjects between school locations are also shown in Table 1. Sixty two percent of mothers and $59.8 \%$ of fathers had an education level up to secondary school. Interestingly, there was a significant association between school location and father's education level $\left(\chi^{2}=8.21, p=0.016\right)$. There were $39.9 \%$ of working mothers, where the proportion was higher among urban mothers $(43.5 \%)$ as compared to rural mothers $(36.8 \%)\left(\chi^{2}=1.80, p=0.208\right)$. As for family size, $45.8 \%$ of the subjects had five to six family members. Based on the $10^{\text {th }}$ Malaysian Plan 2011-2015 classification, $44.0 \%$ parents were classified in the low-income group (<RM2300/month), $19.0 \%$ in the middleincome group (RM2300-5599/month) and $37.0 \%$ in the high-income group (>RM5600). However, no difference was found in parental income group between rural and urban parents. A total of $38.6 \%$ of rural parents were classified in the high-income group as compared to $35.2 \%$ urban parents, whilst $41.2 \%$ of urban parents were classified in the low-income group than their rural counterparts $(46.4 \%)$.

\section{Parental perceptions on their child's BWS}

Table 2 presents the parental perceptions of their child's BWS in comparison with the child's actual BWS. There was a significant difference between parent's perception and the actual body weight of their child $(p<0.001)$. Nearly half of the parents $(45.5 \%)$ misperceived their overweight child as being normal or underweight. Nonetheless, $21.7 \%$ of 
Table 1. Anthropometric characteristics and socio-demographic factors by school location

\begin{tabular}{|c|c|c|c|c|}
\hline Characteristics & $\begin{array}{c}\text { Urban } \\
(n=182)\end{array}$ & $\begin{array}{c}\text { Rural } \\
(n=207)\end{array}$ & $\begin{array}{l}\text { Overall } \\
(n=389)\end{array}$ & $\begin{array}{c}p \text {-value } \\
\left(\chi^{2}\right)\end{array}$ \\
\hline \multicolumn{5}{|c|}{ Anthropometric characteristics, Mean $\pm S D$} \\
\hline Weight (kg) & $35.4 \pm 11.0$ & $32.8 \pm 10.7$ & $34.0 \pm 10.9$ & \\
\hline Height $(\mathrm{cm})$ & $138.6 \pm 7.9$ & $134.4 \pm 8.4$ & $136.4 \pm 8.4$ & \\
\hline BMI z-scores & $-0.2 \pm 1.6$ & $-0.4 \pm 1.6$ & $-0.3 \pm 1.6$ & $0.404^{\ddagger}$ \\
\hline \multicolumn{5}{|l|}{ BMI categories (actual), $n(\%)$} \\
\hline Underweight & $24(13.2)$ & $22(10.6)$ & $46(11.8)$ & 0.700 \\
\hline Normal & $105(57.7)$ & $126(60.9)$ & $231(59.4)$ & $(0.71)$ \\
\hline Overweight & $53(29.1)$ & $59(28.5)$ & $112(28.8)$ & \\
\hline \multicolumn{5}{|c|}{ Mother's education level, $n(\%)$} \\
\hline Primary education & $9(5.2)$ & $15(7.7)$ & $24(6.5)$ & 0.312 \\
\hline Secondary education & $105(60.3)$ & $126(64.3)$ & $231(62.4)$ & $(2.33)$ \\
\hline Tertiary education & $60(34.5)$ & $55(28.1)$ & $115(31.1)$ & \\
\hline \multicolumn{5}{|c|}{ Father's education level, $n(\%)$} \\
\hline Primary education & $11(6.7)$ & $24(12.6)$ & $35(9.8)$ & 0.016 \\
\hline Secondary education & $93(56.4)$ & $120(62.8)$ & $213(59.8)$ & $(8.21)$ \\
\hline Tertiary education & $61(37.0)$ & $47(24.6)$ & $108(30.3)$ & \\
\hline \multicolumn{5}{|c|}{ Mother's current working status, $n(\%)$} \\
\hline Working & 77 (43.5) & $75(36.8)$ & $152(39.9)$ & 0.208 \\
\hline Not working & $100(56.5)$ & $129(63.2)$ & $229(60.1)$ & $(1.80)$ \\
\hline \multicolumn{5}{|l|}{ Family size (member), $n(\%)$} \\
\hline 1 to 4 & $23(12.6)$ & $30(14.5)$ & $53(13.6)$ & 0.770 \\
\hline 5 to 6 & $82(45.1)$ & 96 (46.4) & $178(45.8)$ & $(0.52)$ \\
\hline$\geq 7$ & 77 (42.3) & $81(39.1)$ & $158(40.6)$ & \\
\hline \multicolumn{5}{|c|}{ Household income ${ }^{\S}(\mathrm{RM}), n(\%)$} \\
\hline Low $(<2300)$ & $75(41.2)$ & $96(46.4)$ & $171(44.0)$ & 0.095 \\
\hline Moderate (2300-5599) & 43 (23.6) & $31(15.0)$ & 74 (19.0) & $(4.72)$ \\
\hline High $(>5600)$ & $64(35.2)$ & $80(38.6)$ & $144(37.0)$ & \\
\hline
\end{tabular}

${ }^{\dagger} p$-values for difference between school locations (Pearson's chi-square test)

${ }^{\ddagger} p$-value for the difference between school locations; (independent sample $t$-test)

\$Household income level based on the $10^{\text {th }}$ Malaysian Plan 2011-2015 classification

parents misperceived their thin child as having a normal weight.

The proportion of subjects with correct and incorrect parental perception of BWS compared to the actual BMI in age, gender, school location, family income and family size are presented in Table 3. Overall, of the 389 subjects, $25.7 \%$ of the parents incorrectly perceived their child's BWS regardless of their actual BMI category. Pearson's correlation coefficient was used to determine the relationship between the accuracy of parental perception with socio-demographic variables. While rural area showed a significantly higher percentage of misperception compared to urban $(p=0.027)$, there was no significant association found between parental perceptions and other variables i.e. age, gender, family income and family member. 
Table 2. Parental perceptions of their child's body weight status (BWS) in comparison with actual child's BWS

\begin{tabular}{|c|c|c|c|c|}
\hline \multirow{2}{*}{$\begin{array}{l}\text { Parents' perception of their } \\
\text { child's BWS (n) }\end{array}$} & \multicolumn{3}{|c|}{ Child's actual BWS $(N=389)$} & \multirow[b]{2}{*}{ p-value } \\
\hline & $\begin{array}{c}\text { Thin } \\
(n=46)\end{array}$ & $\begin{array}{l}\text { Normal } \\
(n=231)\end{array}$ & $\begin{array}{l}\text { Overweight } \\
(n=112)\end{array}$ & \\
\hline Underweight ( $n=72$ ) & $36(78.3)$ & $35(15.2)$ & $1(0.9)$ & $<0.001$ \\
\hline Normal ( $n=254)$ & $10(21.7)$ & $193(83.5)$ & $51(45.5)$ & \\
\hline Overweight ( $n=63$ ) & $0(0.0)$ & $3(1.3)$ & $60(53.6)$ & \\
\hline
\end{tabular}

Data presented as frequency (\%)

' $p$-values for difference between parents' perception of their child's BWS and child's actual BWS (Pearson's chi-square)

Table 3. Accuracy of parental perceptions by gender, school location, family income and size

\begin{tabular}{|c|c|c|c|}
\hline \multirow[b]{2}{*}{ Characteristics } & \multicolumn{2}{|c|}{ Parental perceptions } & \multirow[b]{2}{*}{$p$-value } \\
\hline & $\begin{array}{c}\text { Correct } \\
n(\%)\end{array}$ & $\begin{array}{c}\text { Incorrect } \\
n(\%)\end{array}$ & \\
\hline Overall subjects & $289(74.3)$ & $100(25.7)$ & - \\
\hline \multicolumn{4}{|l|}{ Age (years) } \\
\hline 9 & $66(22.8)$ & $20(20.0)$ & 0.119 \\
\hline 10 & 48 (16.6) & $26(26.0)$ & \\
\hline 11 & 175 (60.6) & $54(54.0)$ & \\
\hline \multicolumn{4}{|l|}{ Gender } \\
\hline Male & $106(77.9)$ & $30(22.1)$ & 0.274 \\
\hline Female & $183(72.3)$ & $70(27.7)$ & \\
\hline \multicolumn{4}{|l|}{ School location } \\
\hline Urban & $145(79.7)$ & 37 (20.3) & 0.027 \\
\hline Rural & $144(69.6)$ & $63(30.4)$ & \\
\hline \multicolumn{4}{|c|}{ Family income (RM) } \\
\hline$<2300$ & $128(74.9)$ & $43(25.1)$ & 0.843 \\
\hline $2300-5599$ & $53(71.6)$ & $21(28.4)$ & \\
\hline$>5600$ & $108(75.0)$ & $36(25.0)$ & \\
\hline \multicolumn{4}{|c|}{ Family size (member) } \\
\hline 1 to 4 & $40(75.5)$ & $13(24.5)$ & 0.750 \\
\hline 5 to 6 & $129(72.5)$ & $49(27.5)$ & \\
\hline$\geq 7$ & $120(75.9)$ & $38(24.1)$ & \\
\hline
\end{tabular}

${ }^{\dagger} p$-values for difference between correct and incorrect parental perceptions (Pearson's chisquare test)

Physician's opinion on child's BWS and parental attitude towards the health effects of obesity

The history of physician's opinion on child's BWS versus actual BWS is presented in Table 4. Almost twenty percent $(19.6 \%)$ of parents with overweight children were told by their physician about their child's weight problem $(p<0.001)$. Meanwhile, 26.1\% 
Table 4. History of physician's opinion on child's body weight status, parental attitude towards the health effects of obesity vs. actual BMI categories

\begin{tabular}{lll}
\hline \multirow{2}{*}{ Characteristics } & \multicolumn{3}{c}{ Actual body weight status } & \\
\cline { 2 - 3 } & Thin & Normal
\end{tabular}

History of physician's opinion on child's

body weight status, $\mathrm{n}(\%)$

Did your physician ever tell you that your child is overweight?

$\begin{array}{lcccc}\text { Yes } & 0(0.0) & 2(0.9) & 22(19.6) & <0.001 \\ \text { Never } & 46(100.0) & 229(99.1) & 90(80.4) & \\ \text { our physician ever tell you that } & & & & \\ \text { yur child is underweight? } & 12(26.1) & 15(6.5) & 4(3.6) & <0.001 \\ \text { Yes } & 34(73.9) & 216(93.5) & 108(96.4) & \end{array}$

Percentage (\%) agree or strongly agree vs. actual body weight status

I am worried about my child's weight right now

$\begin{array}{rrrr}54.3 & 16.5 & 56.3 & <0.001^{\dagger} \\ 65.2 & 56.3 & 58.9 & 0.844^{\dagger} \\ 84.8 & 71.0 & 67.9 & 0.349^{\dagger} \\ 71.7 & 50.6 & 56.3 & 0.252^{\dagger} \\ 65.2 & 64.5 & 60.7 & 0.795^{\dagger}\end{array}$

Overweight children are likely to become overweight adults

Overweight children are more likely to develop diabetes (high blood sugar) than children who are not overweight

Overweight children are more likely to have problems in their social relationships with other children who are not overweight

Eating habits of parents influence the eating habits of their children

Pearson's chi-square test

${ }^{\dagger} p$-values for differences between parental attitude towards health effects of obesity $v$ s. actual body weight status (Pearson's chi-square test)

(Physician refers to any medical doctor which the parents and the children meet during checkup at any clinic or hospital)

of parents with an underweight child reported being told by their physician that their child was underweight as compared to parents with normal $(6.5 \%)$ and overweight $(3.6 \%)$ children.

More than half of the parents of overweight $(56.3 \%)$ and underweight (54.3\%) children were worried about their child's BWS $(p<0.001)$ (Table 4). Majority of parents (65.2\%) agreed that overweight children were more likely to become obese during adulthood, develop diabetes and have problems with their social relationships compared to children with normal body weights. Parents of children in all BMI groups held similar opinions about the influence of parents' eating habits on the eating habits of their children. 


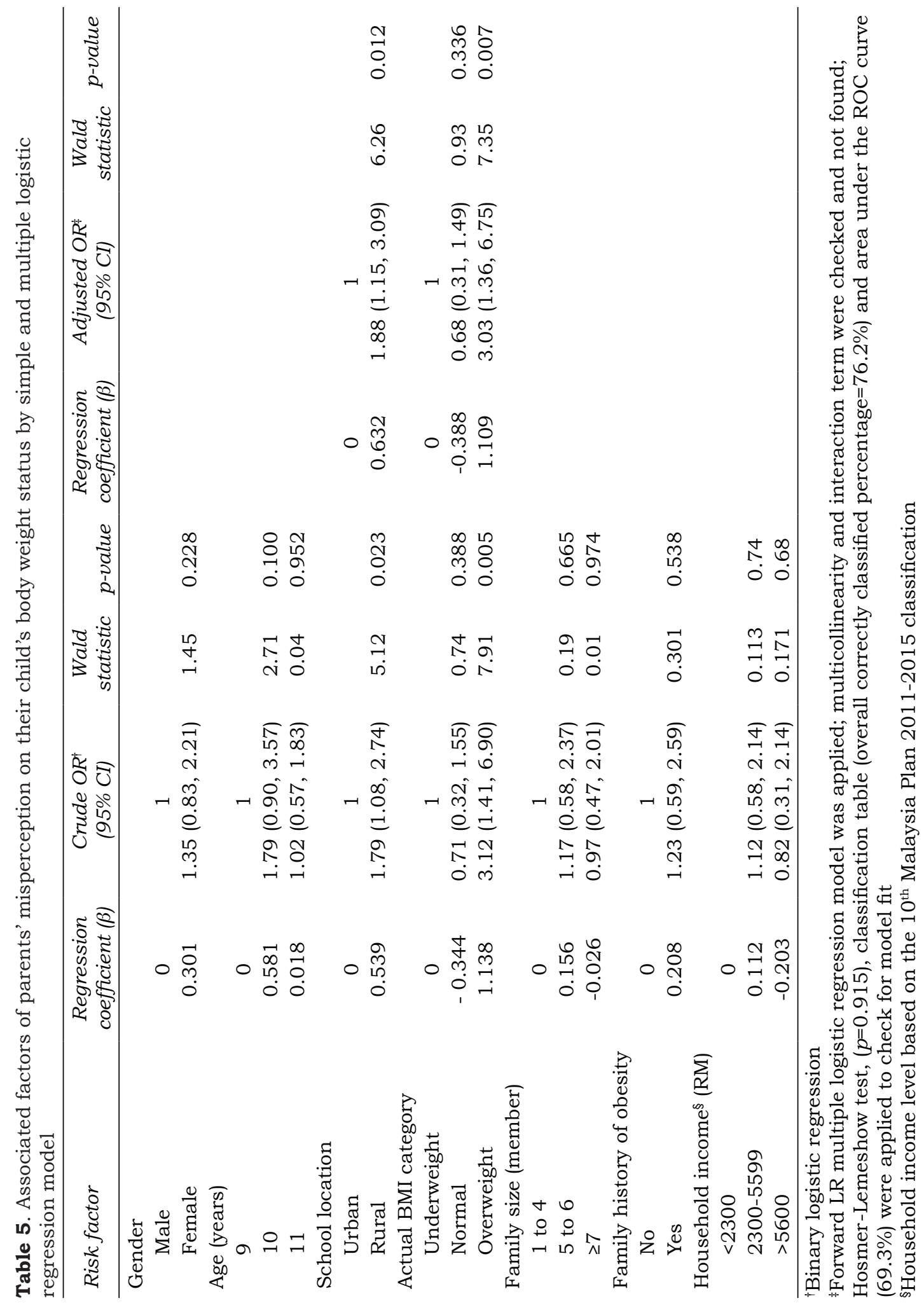




\section{Factors related with parental} misperceptions

Logistic regression analysis was used to identify the predictors for the misclassification of parent's perceived BWS as compared to actual measurements. Crude and Adjusted Odds Ratio (OR) from simple and multiple logistic regression are presented in Table 5, respectively. Out of seven variables which were age, gender, school location, actual BMI categories, family income, family history of obesity and family size, two variables were found to be statistically significant predictors for parents' misperceptions. The analysis revealed that the greatest predictor of parental misperceptions was the child's actual BWS, followed by school location. Parents of overweight children $(O R=3.03)$ and rural school children $(O R=1.88)$ were more likely to misperceive their child's BWS, after controlling for gender, age, family size, family history of obesity and household income. The HosmerLemeshow Test $\left(\chi^{2}=0.968\right.$, degrees of freedom $=4 ; \quad p=0.915$ ) indicated that numbers of misclassification were not significantly different from those predicted by the model and the overall model fit was good. There was no significant association between the misclassification of parent's perceived BWS and other factors (gender, age, family size, family history of obesity and household income).

\section{DISCUSSION}

To our knowledge, this is the first study that attempted to identify parental misperception of BWS among school children in Kuala Terengganu, Malaysia and to explore the factors associated with such misperception. The current findings confirmed the observation from previous studies that a substantial percentage of parents inaccurately categorise their child's BWS. Almost twenty-six percent $(25.7 \%)$ of parents in this study misperceived their child's BWS. This finding is comparable from that of Muhamad et al. (2008) who reported a higher percentage of misperception (38.2\%) among 204 parents of 9 to 12 years old children in Kuala Lumpur. The study also suggested that knowledge on nutrition and obesity among parents was not associated with the ability to recognise the development of overweight and obesity problems among their children. Similarly, another local study by Serene Tung et al. (2011) also found a total of $50.8 \%$ parents who had an incorrect perception of their child's BWS. However, the researchers pooled the findings on misperception, which included the over-estimators (12.8\%), under-estimators (19.6\%) and non-estimators (18.4\%). Only 49.2\% of the parents correctly perceived their children's weight (correct estimators). Nonetheless, the available evidence seems to suggest that the accuracy of parental perceptions of their child's BWS has not changed from previous studies (Gerards et al., 2014; Tompkins et al., 2015).

This study found notable proportions of misperceptions among parents on their child's BWS. Only 53\% of the parent's perceptions of overweight children had an agreement with the actual BWS. In line with a previous finding (Karunanayake et al., 2016), this study reported that almost half of the parents of overweight children (46.4\%) failed to accurately categorise their child's BWS. Parry et al. (2008) suggested that misperception among parents regarding their child's BWS increases as population gets fatter. This is based on the presumption that "what is common is alright", thus making heavier weight become more culturally acceptable (Parry et al., 2008). The tendency of these parents to minimise issues related 
to overweight might also be intensified especially when majority of the family members are obese, or when excess body weight is something common in their living community (Francescatto et al., 2014). This is further supported by the increasing prevalence of childhood obesity among low- and middle-income Asian countries, which have become home to nearly half of the world's obese children (WHO, 2016). In Malaysia, the National Health and Morbidity Survey (NHMS) in the year 2015 (IPH, 2015) reported that $11.9 \%$ children aged $<18$ years were obese, which almost doubled from 6.1\% in 2011 (IPH, 2011). Another potential explanation for the misperception may be due to the gradual changes in a child's body weight including both muscle and fat that occur over time, which are often unnoticeable, thus ignored by parents. Eventually, due to the gradual shift of weight, parents failed to recognise when their children have become overweight or obese (Hansen et al., 2014). Nonetheless, parental misperception regarding their child's BWS is hypothesised to be associated with the "theory of idealisation", in which parents idealise their child to be of a normal size (Hager et al., 2012). This may be due to cultural influence which often regards high body weight as a sign of successful parenting, especially during early childhood (Southwell \& Fox, 2011).

Previous studies have linked discrepancy between parental perception and actual BWS of children with several associated factors. Gender of the child possibly influences the parent's classification of BWS (Karunanayake et al., 2016). In contrast with earlier findings (De La O et al., 2009; Maynard et al., 2003), this study reported no significant gender difference in percentage of misperception among parents. Maynard et al. (2003) reported that mothers of overweight daughters were three times more likely to misclassify their child's BWS as compared to mothers of overweight sons. This indicated that parents may have a different set of thresholds regarding overweight status between gender. Besides, since females are known to have a higher recognition of body image and body weight concerns compared to males, it may also trigger parents to pay more attention to girls' body image than that of boys'. Not only that, a previous finding found that the age of the children could also influence parents' perceptions (Duncan et al., 2015). However, in the present study, there was no relationship found between the child's age and parent's perception. In contrast, a study by Júliusson et al. (2011) reported that parents were more likely to underestimate their younger overweight children (2-5 years old), whilst in older children, parents tended to overestimate their underweight teenagers (12-19 years old). They suggested that parents who underestimated their young children were reluctant to label their toddler as overweight due to misconception that weight gains during this stage reflected healthy growth in children. Conversely, parents who misclassified their underweight teenagers as being normal may have distortion in healthy body image. Nevertheless, there are several socio-economic factors such as parental education level and family income that may influence parental perceptions of their child's BWS (Hansen et al., 2014). In agreement with previous studies, this study found no relationship between socio-economic status and parental perceptions of their child's BWS. Nonetheless, a previous study by Hearst et al. (2011) reported 8.92 times higher odds of misperception in overweight children by non-college-graduated parents as compared to four times higher odds among college-graduated parents. This rather contradictory result may be 
owing to the difference in the studied population.

Although a high percentage of parents with overweight children underestimated their child's body weight status, only $56.3 \%$ of these parents were found to be worried about their child's body weight and agreed with the health and psychosocial effects of obesity. A possible explanation for this finding may be related to the "optimistic bias" of personal risk (Weinstein, 1989). These parents simply deny the fact that their child is overweight or obese and use this bias as a coping strategy when confronted with the health risks of obesity (Myers \& Vargas, 2000). In other words, parents who operate under this situation distort their views from the possible consequences of overweight on their children. However, despite the high prevalence of overweight reported in this study, only one out of five parents of overweight children reported being told by a clinician about their child's body weight problem. This intriguing finding may be due to a lack in routine healthcare follow-up or misreporting among parents. There are possibilities that clinicians did not inform parents about their children's body weight status as a health risk. Based on the 1999 to 2002 analysis of the National Health and Nutritional Survey (NHANES) by the Centre for Disease Control and Prevention (CDC), it was reported that only $36.7 \%$ of overweight children aged 2 to 19 years were told by their clinicians that they were overweight. Since early detection of obesity and its related consequences are crucial, clinicians are expected to convey the information to parents to ensure a better understanding on the definition of childhood obesity and to increase their awareness of their child's body weight status (Rietmeijer-Mentink et al., 2013).

Previous studies have found large variabilities in the predictors influencing parental perception of their child's BWS
(Gerards et al., 2014; Karunanayake et al., 2016). The current study found that the strongest predictor related to the inaccuracy of parental perception of their child's BWS was having an overweight child. Secondly, the most interesting finding from the logistic regression analysis was that parents from rural areas were twice more likely to misclassify their child's BWS as compared to their urban counterparts. These findings are important for Terengganu stakeholders particularly in the Kuala Terengganu district as this district has a higher prevalence of childhood obesity in the rural (14.1\%) compared to the urban area (12.7\%) (Nurzaime et al., 2017). Despite Kuala Terengganu being the capital district of Terengganu, there are underprivileged and underdeveloped areas which are associated with lower socioeconomic status (SES). Previous studies have reported an association between low SES particularly parental education level with a higher percentage of misperception of child's weight among parents, indicating that families with lower education level and economic background probably have decreased level of awareness about healthy body weight (Hearst et al., 2011). The present study also found that parents with overweight children (those with $\mathrm{BAZ}>1 \mathrm{SD}$ ) were three times more likely to have inaccurate perceptions of their child's BWS. Additionally, a previous study by Huang et al. (2009) found that parents with at-risk-of-overweight (AROW) and overweight children were $67 \%$ less likely to recognise their own child's BWS as compared with their normal and underweight counterparts (OR=0.33, 95\% CI: 0.23, 0.46). The findings reported in this study suggested the association between parental misperception of their child's body weight and low health literacy leading to distorted perception of healthy weight. Therefore, this warrants an active role 
of healthcare providers in informing all parents of overweight children on the risks of obesity-related health problems and its co-morbidities, and offer familybased body weight control interventions.

The high percentage of parental misperception from the present study provided evidence to support the conceptual premise that parental recognition of their child's BWS is the precursor and a critical component of successful weight management practices in children. Furthermore, parental perception on their child's BWS may determine the level of support on health, activity and behaviour of the family. The ability of parents to correctly identify their child's body weight problem often indicate their concern and intention to positively modify their family lifestyle and behaviours compared to parents who overlook the problem. However, contradicting to popular belief, Robinson and Sutin (2016) found that the ability of parents to identify weight problem of their children did not act as a protective factor against obesity. Instead, it led to further weight gain across childhood. The stigma and label that were attached to the children not only increased the risk of lower self-esteem and unhealthy weight-control behaviours; it may also change the way parents treat their children. Children who are viewed as overweight by their parents tend to gain more weight across childhood, irrespective of their initial BMI. These parents are more likely to encourage unhealthy eating, serve larger meals and may believe that their child's body weight itself prevents the child from doing exercises, which eventually leads to further weight gains (Robinson \& Sutin, 2016). Therefore, a study proposed that instead of commenting on their child's body weight, parents should provide a home environment that nurtures healthy eating and active behaviours in the family (Neumark-sztainer et al., 2011).
In addition, healthcare providers can play an important role by discussing and advising the parents about their child's BWS, thus suggesting management strategies to control the associated problems.

\section{Strengths and limitations}

This study was the first attempt to assess the perceptions of parents from Terengganu on BWS of their children, which offered some insights on the factors that influence their perceptions. The most meaningful finding from this study was that both parents with overweight children and those from rural areas had difficulties understanding their children's BWS. Therefore, the information presented herein will serve as an accurate baseline quantitative data that can be used in planning future research. BWS based on height and weight measured by trained personnel has reduced the potential of bias compared with studies that used self-reported data.

The present study did not cover other related factors especially parental BWS and parenting styles, which may also be associated with parent's perception of their child's BWS. Furthermore, the study design was cross-sectional and therefore could only describe the association between parental perception of child's BWS and child's actual BWS, and also parental concern about their child's body weight and health, but obviously could not explain the causality effect. This study also did not include pubertal assessment using Tanner staging, thus may have overlooked the influence of a child's pubertal and maturity stage on parental perception of his/ her BWS.

\section{CONCLUSION}

This study highlighted that majority of parents failed to accurately determine 
their child's BWS. Parental misperception on their child's BWS particularly on those with weight problems potentially impedes the intervention and prevention against obesity. Parental acknowledgement of body weight problem among their children is crucial as the initial step of promoting positive behaviours among the family members. Moreover, parental identification reflects the level of parental understanding with regards to BWS and health. Apparently, parents from rural area and those having overweight children were more likely to have a misperception of their child's BWS. Therefore, novel strategies that are culturally-tailored to this population are required to improve parental identification of their child's BWS. Additionally, health-care providers also play an important role in identifying children with body weight problems and assisting parents with suitable familybased obesity prevention strategies. This research has thrown up many questions that require further research to understand on how parental perception of their child's BWS may affect further weight gain and future health outcomes among these children.

\section{Acknowledgement}

The authors would like to acknowledge the Malaysian Ministry of Education and Terengganu State Education Department for the permission granted to conduct this study. Enormous appreciation extended to the participating school children and their caregivers, all teachers and school administrators, enumerators and to all members of the Health of Adolescents in Terengganu study (HATs). Funding for this research was provided by the Malaysian Ministry of Higher Education's Fundamental Research Grant Scheme (FRGS/2/2013/SKK/UNISZA/01/1).

\section{Authors' contribution}

NZ, made substantial contributions to the acquisition of data, analysis and interpretation of data, and also participated in manuscript writing, drafting and revising it critically for important intellectual content; AA, principal investigator, grant owner, made major contributions to the conception and design, methodology, acquisition of data, analysis and interpretation of data, drafting, writing and revising of the manuscript; MRS, made substantial contributions to methodology, acquisition analysis and interpretation of data, and also participated in the drafting of the manuscript and revising it critically for important intellectual content; AA, made substantial contributions to the idea, conception and design, methodology, acquisition of data, statistical analysis and interpretation of data, and also participated in drafting of the manuscript and revising it critically for important intellectual content.

\section{Conflict of interest}

All authors declare no potential conflict of interest with respect to the research, authorship, and/or publication of this article.

\section{References}

Chen HY, Lemon SC, Pagoto SL, Barton BA, Lapane KL \& Goldberg RJ (2014). Personal and parental weight misperception and selfreported attempted weight loss in US children and adolescents, National Health and Nutrition Examination Survey, 2007-2008 and 20092010. Prev Chronic Dis 11:E132.

De La OA, Jordan KC, Ortiz K, Moyer-Mileur LJ, Stoddard G, Friedrichs M, Cox R, Carlson EC, Heap E \& Mihalopoulos NL (2009). Do parents accurately perceive their child's weight status? $J$ Pediatr Heal Care 23: 216-221.

Duncan DT, Hansen AR, Wang W, Yan F \& Zhang J (2015). Change in misperception of child's body weight among parents of American preschool children. Child Obes 11:384-393.

Eckstein KC, Mikhail LM, Ariza AJ, Thomson JS, Scott C, Binns HJ, Eckstein KC, Mikhail LM, Ariza AJ, Thomson JS, Millard SC \& Binns HJ (2006). Parents' perceptions of their child's weight and health. Pediatrics 117:681-690.

Francescatto C, Santos NS, Coutinho VF \& Costa RF (2014). Mothers' perceptions about the nutritional status of their overweight children: A systematic review. J Pediatr (Rio. J). 90:332343 .

Genovesi S, Giussani M, Faini A, Vigorita F, Pieruzzi F, Strepparava MG, Stella A \& Valsecchi MG (2005). Maternal perception of excess weight in children: a survey conducted by paediatricians in the province of Milan. Acta Paediatr 94:747752 .

Gerards SM, Gubbels JS, Dagnelie PC, Kremers SPJ, Stafleu A, de Vries NK \& Thijs C (2014). Parental perception of child's weight status and subsequent BMIz change: the KOALA birth cohort study. BMC Public Health 14:291. 
Hager ER, Candelaria M, Latta LW, Hurley KM, Wang Y, Caulfield LE \& Black MM (2012). Maternal perceptions of toddler body size. Arch Pediatr Adolesc Med 166:417-422.

Hansen AR, Duncan DT, Tarasenko YN, Yan F \& Zhang J (2014). Generational shift in parental perceptions of overweight among school-aged children. Pediatrics 134:481-488.

Hearst MO, Sherwood NE, Klein EG, Pasch KE \& Lytle LA (2011). Parental perceptions of their adolescent's weight status: The ECHO study. Am J Health Behav 35:248-255.

Huang JS, Donohue M, Becerra K \& Xu R (2009). Relationship between parents' and children's weight perceptions results of a survey. ICAN Infant, Child, Adolesc Nutr 1:1-4.

IPH (2011). National Health and Morbidity Survey (NHMS) 2011. Vol. II: Non-Communicable Diseases. Institute of Public Health, Kuala Lumpur.

IPH (2015). National Health and Morbidity Survey (NHMS) 2015. Vol. II: Non-Communicable Diseases, Risk Factors \& Other Health Problems. Institute of Public Health, Kuala Lumpur.

Johnson R, Welk G, Saint-Maurice PF \& Ihmels M (2012). Parenting styles and home obesogenic environments. Int $J$ Environ Res Public Health 9:1411-1426.

Jones A, Parkinson K, Drewett R, Hyland R, Pearce M \& Adamson A (2011). Parental perceptions of weight status in children: the Gateshead Millennium Study. Int J Obes 35:953-962.

Júlíusson PB, Roelants M, Markestad T \& Bjerknes $R$ (2011). Parental perception of overweight and underweight in children and adolescents. Acta Paediatr Int J Paediatr 100:260-265.

Karunanayake C, Rennie D, Hildebrand C, Lawson J, Hagel L, Dosman J \& Pahwa P (2016). Actual body weight and the parent's perspective of child's body weight among rural Canadian children. Children 3:13.

Katz DL (2015). Oblivobesity: Looking over the overweight that parents keep overlooking. Child Obes 11:13-14.

Kok HL \& Yit SC (2019). Comparison of paternal and maternal feeding practices and parenting styles between healthy weight and overweight or obese primary school children. Malaysian $J$ Med Heal Sci 15:2-9.

Maynard LM, Galuska DA, Blanck HM \& Serdula MK (2003). Maternal perceptions of weight status of children. Pediatrics 111:1226-1231.
Muhammad NA, Omar K, Shah SA, Muthupalaniappen L \& Arshad F (2008). Parental perception of their children's weight status, and its association with their nutrition and obesity knowledge. Asia Pac J Clin Nutr 17:597-602.

Myers S \& Vargas Z (2000). Parental perceptions of the preschool obese child. Pediatr Nurs 26:2330.

Neumark-sztainer D, Bauer KW, Friend S, Hannan PJ, Story M \& Berge JM (2011). Family weight talk and dieting: How much do they matter for body dissatisfaction and disordered eating behaviors in adolescent girls? J Adolesc Heal 47:270-276.

Nurzaime Z, Aryati A, Nor Saidah AM, Amin RM, Shahril MR, Wafa SW, Fadzli SA \& Ahmed A (2017). Influence of school location within districts of Terengganu on body weight status among school adolescents. Int $J$ Acad Res Bus Soc Sci 7:1166-1173.

Parry LL, Netuveli G, Parry J \& Saxena S (2008). A systematic review of parental perception of overweight status in children. J Ambul Care Manage 31:253-268.

Rietmeijer-Mentink M, Paulis WD, van Middelkoop M, Bindels PJE \& van der Wouden JC (2013). Difference between parental perception and actual weight status of children: A systematic review. Matern Child Nutr 9:3-22.

Robinson E \& Sutin AR (2016). Parental perception of weight status and weight gain across childhood. Pediatrics 137:e20153957e20153957.

Rosenkranz RR \& Dzewaltowski DA (2008). Model of the home food environment pertaining to childhood obesity. Nutr Rev 66:123-140.

Serene Tung EH, Shamarina S \& Mohd Nasir MT (2011). Familial and socio-environmental predictors of overweight and obesity among primary school children in Selangor and Kuala Lumpur. Mal J Nutr 17:151-162.

Sleddens EFC, Kremers SPJ, Stafleu A, Dagnelie PC, De Vries NK \& Thijs C (2014). Food parenting practices and child dietary behavior. Prospective relations and the moderating role of general parenting. Appetite 79:42-50.

Southwell O \& Fox JRE (2011). Maternal perceptions of overweight and obesity in children: a grounded theory study. $\mathrm{Br} \mathrm{J}$ Health Psychol 16:626-41. 
Tompkins CL, Seablom M \& Brock DW (2015). Parental perception of child's body weight: a systematic review. J Child Fam Stud 24:13841391.

Tschamler JM, Conn KM, Cook SR \& Halterman JS (2010). Underestimation of children's weight status: views of parents in an urban community. Clin Pediatr 49:470-476.

Weinstein N (1989). Optimistic biases about personal risks. Science 246:1232-1233.

WHO (2007). In: Growth reference data for 5-19 years. From http://www.who.int/growthref/ en/ [Retrieved October 10 2016].
WHO (2009). WHO AnthroPlus for personal computers manual software for assessing growth of the world's children. World Health Organization. Geneva, Switzerland.

WHO (2016). Report on the comission on ending childhood obesity. World Health Organization. Geneva, Switzerland.

Young-Hyman D, Herman LJ, Scott DL \& Schlundt DG (2000). Care giver perception of children's obesity-related health risk: a study of African American families. Obes Res 8:241-248. 